\title{
ĐẶC ĐIỂM LÂM SÀNG, CÂ̂N LÂM SÀNG VÀ TÌNH TRANG DI CĂN HẠCH CỦA UNG THƯ TUYẾN GIÁP THỂ TỦY
}

Nguyễn Xuân Hậu ${ }^{1}$

\section{TÓM TẮT}

Mục tiêu: đánh giá đặc điểm lâm sàng, cận lâm sàng và tình trang di căn hạch trong ung thư tuyến giáp thể tủy. Đối tượng và phương pháp: Thiết kế kết hợp hồi cứu và tiến cứu trên 34 bệnh nhân chậ̂n đoán ung thư biểu mô tuyến giáp thể tủy được phẩu thuật tại bệnh viện đại học $Y$ Hà Nội từ $1 / 1 / 2015$ đến $30 / 06 / 2020$. Kết quả: Tuổi mắc bệnh trung bình là $48,1 \pm 11,2$, tỉ lệ nữ/nam là $1 / 1,26$. Đa số bệnh nhân khám sức khỏe định kỳ phát hiện có u giáp (55,9\%). Khối u chủ yếu được đánh giá TIRADS 4 trên siêu âm $(76,5 \%)$, tỉ lệ chọc hút tế bào kim nhỏ khẳng định hoặc nghi ngờ ác tính là $55,9 \%$. Tất cả bênh nhân được cắt tuyến giáp toàn bô + vét hach cổ. Tỉ lê di căn hạch chung là 47,1\%, di căn hạch nhóm 6 đớn thuần và kèm theo hach cổ bên lần lượt là $31,2 \%$ và $62,5 \%$. Tỉ lệ di căn hạch tiềm ẩn là $21,1 \%$. Nam giới là một yếu tố làm tăng tỉ lệ di căn hạch có ý nghĩa thống kê $(p<0,05)$. Kết luận: ung thư tuyến giáp thế tủy khó chẩn đoán trên tế bào, tỷ lệ di căn hạch cao.

Từ khóa: ung thư tuyến giáp thể tủy, di căn hạch.

\section{SUMMARY}

\section{CLINICOPATHOLOGICAL AND NODAL METASTASIS CHARACTERISTICS OF MEDULLARY THYROID CANCER}

Objective: To evaluate the clinicopathological and nodal metastasis characteristics of medullary thyroid cancer. Subject and methods: retrospective combined with prospective cohort study of 34 medullary thyroid carcinoma patients treated by surgery at Hanoi Medical University Hospital from $1^{\text {st }}$ January 2015 to $30^{\text {th }}$ Jun 2020. Results: The mean age was $48.1 \pm 11,2$ and the ratio of female/male was $1.26 / 1$. Most patients presented with an asymptomatic (55.9\%). $76.5 \%$ of tumors were classified as TIRADS 4 on ultrasound and FNA gave defined or suspicious for medullary thyroid cancer result in $55.9 \%$ of cases. All patients had undergone total thyroidectomy and neck dissection. The overall rate of nodal metastasis was $47.1 \%$. Central neck compartment nodal metastasis only was detected in $31.2 \%$ cases, while $62.5 \%$ of patients had positive nodes in both central and lateral neck. The occult nodal metastasis rate was $21.1 \%$. The analysis showed that the nodal metastasis was significantly related with the male sex $(p<0.05)$. Conclusion: MTC are difficulty diagnosed in clinique, cervical lymph node metastasis rate is high.

\section{${ }^{1}$ Bệnh viện Đại học Y Hà Nội}

Chịu trách nhiệm chính: Nguyễn Xuân Hậu

Email: drnguyenxuanhau@gmail.com

Ngày nhận bài: 12.7.2021

Ngày phản biện khoa học: 7.9.2021

Ngày duyệt bài: 14.9.2021
Keyword: medullary thyroid cancer, lymph node metastasis.

\section{I. ĐẶT VẤN ĐỀ}

Ung thư biểu mô tuyến giáp là loại ung thư phổ biến nhất của hể nội tiết (chiếm $90 \%$ ) ${ }^{1}$. Ung thư tuyến giáp gồm 4 thể chính là ung thư thể nhú, ung thư thể nang, ung thư thể tủy và ung thư thể không biệt hóa trong đó thể tủy chiếm $3-5 \%{ }^{2}$. Ung thư tuyến giáp thể tủy có nguồn gốc từ tế bào $C$ của tuyến giáp, đây là thể bệnh có tiên lượng xấu trong các thể của ung thư tuyến giáp. Trong ung thư tuyến giáp thể tủy tỉ lê di căn hach cổ tại thời điểm chẩn đoán lên tới $65 \%{ }^{3}$. Thời gian sống thêm trung bình của bệnh nhân ung thư tuyến giáp thể tủy thấp hơn so với thể nhú hoặc nang ${ }^{4}$. Khác với ung thư tuyến giáp biệt hóa trong ung thư tuyến giáp thể tủy calcitonin và CEA được coi làm chất chỉ điểm theo dõi tái phát ${ }^{5}$.

Đánh giá về đặc điểm bệnh học và điều trị phẫu thuật của bệnh nhân ung thư tuyến giáp thể tủy đã được trình bày ở các nghiên cứu trên thế giới, tuy nhiên tại Việt Nam còn chưa được nghiên cứu nhiều. Vì vậy chúng tôi đã thực hiện nghiên cứu đề tài này với mục tiêu: Đánh giá đặc điểm lâm sàng, cận lâm sàng và tình trạng di căn hạch của ung thư tuyến giáp thể tủy.

\section{II. ĐỐI TƯỢNG VÀ PHƯƠNG PHÁP NGHIÊN CỨU}

2.1. Đối tượng nghiên cứu: Nghiên cứu được thực hiện trên 34 bệnh nhân chẩn đoán ung thư biểu mô tuyến giáp thể tủy được phẫu thuật tại bệnh viện đại học Y Hà Nội từ 1/1/2015 đến 30/06/2020.

\section{Tiêu chuẩn lựa chọn bệnh nhân}

- Bệnh nhân được chẩn đoán ung thư tuyến giáp được phẫu thuật cắt tuyến giáp và vét hạch theo phác đồ có kểt quả xét nghiệm giải phẫu bệnh khẳng định là ung thư biểu mô tuyến giáp thể tủy.

- Hồ sơ bệnh án đầy đủ kết quả: khám lâm sàng, cận lâm sàng trước và sau mổ.

- Bệnh nhân đồng ý tham gia nghiên cứu.

Tiêu chuẩn loại trừ

- Bệnh nhân đãa được phẫu thuật ung thư tuyến giáp tai tuyến trước.

- Bệnh nhân cũ đến điều trị tiếp vì tái phát, di căn hoặc lý do khác.

2.2. Phương pháp nghiên cứu: Nghiên 
cứu mô tả hồi cứu kết hợp tiến cứu.

\subsection{Các chỉ số nghiên cứu}

- Khai thác các thông tin lâm sàng, cận lâm sàng (siêu âm tuyến giáp đánh giá kích thước $u$, số lượng u, phân loại TIRADS, tình trạng di căn hạch cổ và chọc hút tế bào trước mổ)

- Hạch không phát hiện di căn trước mổ được xác định qua khám lâm sàng và siêu âm vùng cồ

- Phân loại TIRADS được sử dụng theo TIRADS Jin Young Kwak (2011), phân loại giai đoạn bệnh theo AJCC 2017.

- Phương pháp phẫu thuật:

- Cắt tuyến giáp toàn bộ khi phát hiện hạch di căn, u kích thước $>1 \mathrm{~cm}$, hoặc xâm lấn cơ trước giáp.

- Vét hạch cổ trung tâm là bắt buộc khi khẳng định ung thư tuyến giáp thể tủy.

- Vét hạch cổ trung tâm kèm vét hạch cổ bên điều trị khi lâm sàng và cận lâm sàng phát hiện hach trước mổ.

- Kết quả giải phẫu bệnh sau mổ, khám theo dõi định kỳ sau mổ.

\section{KẾT QUẢ NGHIÊN CỨU}

3.1. Đặc điểm lâm sàng và cận lâm sang. Độ tuổi trung bình của các bệnh nhân trong nghiên cứu là $48,1 \pm 11,2$, trong đó bênh nhân nhỏ tuổi nhất là 23 tuổi, cao tuổi nhất là 70 tuổi. Lứa tuổi hay gặp nhất là 40-65 tuổi, chiếm tỉ lệ $67,6 \%$. Nam giới mắc nhiều hơn nữ, tỉ lệ nữ/nam là $1 / 1,26$.

Đa số bệnh nhân khám sức khỏe định kỳ phát hiện có u giáp, lý do vào viện này chiếm tỉ lệ $55,9 \%$. Bệnh nhân tự sờ thấy u vùng cổ hoặc hạch cổ có tỉ lệ $35,3 \%$. Các nguyên nhân khác: nuốt vướng, khàn tiếng ít gặp. Có $88,6 \%$ bệnh nhân đến viện trong vòng 6 tháng từ khi phát hiện bệnh.

Bảng 1: Đặc điểm khôi u giáp qua siêu âm trước mố

\begin{tabular}{|c|c|c|c|}
\hline & hỉ số & $\begin{array}{c}\text { Số bệnh nhâr } \\
(\mathrm{n}=34)\end{array}$ & Tỉ lệ \\
\hline & $\leq 1 \mathrm{~cm}$ & 10 & 29,4 \\
\hline Kích & $1 \mathrm{~cm}<\mathrm{u} \leq 2 \mathrm{~cm}$ & 9 & 26,5 \\
\hline thước u & $2 \mathrm{~cm}<\mathrm{u} \leq 4 \mathrm{~cm}$ & 13 & 38,2 \\
\hline & $>4 \mathrm{~cm}$ & 2 & 5,9 \\
\hline Số lượng & Đơn ố & 26 & 76,5 \\
\hline $\mathrm{u}$ & Đa ố & 8 & 23,5 \\
\hline & Một thùy & 28 & 82,4 \\
\hline Vị trí u & Eo giáp & 0 & 0 \\
\hline & Hai thùy & 6 & 17,6 \\
\hline & 3 & 1 & 2,9 \\
\hline TIRADS & 4 & 26 & 76,5 \\
\hline & 5 & 7 & 20,6 \\
\hline
\end{tabular}

Bảng 2: Kêt quả chọc hút tế bào băng kim nhỏ

\begin{tabular}{|c|c|c|}
\hline Kết quả & $\begin{array}{c}\text { Số BN } \\
(\mathbf{n = 3 4 )}\end{array}$ & $\begin{array}{c}\text { Tỉ lế } \\
\mathbf{( \% )}\end{array}$ \\
\hline Dương tính thế tủy & 5 & 14,7 \\
\hline Nghi ngờ thế tủy & 14 & 41,2 \\
\hline $\begin{array}{c}\text { Hướng ung thư giáp } \\
\text { thể nhú }\end{array}$ & 8 & 23,5 \\
\hline Ám tính & 7 & 20,6 \\
\hline
\end{tabular}

Sinh thiết tức thì trong mố: tỷ lệ STTT trong mổ là $70,6 \%$.

\subsection{Tình trang di căn hach \\ Bảng 3: Kểt quả di căn hạch sau phẫu} thuật

\begin{tabular}{|c|c|c|c|}
\hline \multicolumn{2}{|c|}{$\begin{array}{c}\text { Kết quả di căn hạch sau } \\
\text { phẫu thuật }\end{array}$} & \multirow{2}{*}{$\begin{array}{c}\begin{array}{c}\text { Số } \\
\text { bệnh } \\
\text { nhân }\end{array} \\
5\end{array}$} & \multirow{2}{*}{$\begin{array}{l}\begin{array}{l}\text { Tỉ lệ } \\
(\%)\end{array} \\
31,2\end{array}$} \\
\hline \multirow{3}{*}{$\begin{array}{l}\text { Vị trí hăch di } \\
\text { căn } \\
\quad(n=16)\end{array}$} & $\begin{array}{l}\text { Nhóm trung tâm } \\
\text { đơn thuẩn }\end{array}$ & & \\
\hline & $\begin{array}{l}\text { Nhóm hạch cố } \\
\text { bên đơn thuần }\end{array}$ & 1 & 6,3 \\
\hline & $\begin{array}{l}\text { Nhóm trung tâm } \\
+ \text { hạch cố bên }\end{array}$ & 10 & 62,5 \\
\hline $\begin{array}{l}\text { Không phát } \\
\text { hiện hach }\end{array}$ & $\begin{array}{l}\text { Khống di căn } \\
\text { hạch }\end{array}$ & 15 & 78,9 \\
\hline $\begin{array}{c}\text { trước mổ qua } \\
\text { khám lâm } \\
\text { sàng và siêu } \\
\text { âm vùng cổ } \\
(\mathrm{n}=19)\end{array}$ & Có di căn hạch & 4 & 21,1 \\
\hline
\end{tabular}

Tất cả bệnh nhân đều được cắt tuyến giáp toàn bộ và vét hạch cổ. Tî lệ vét hạch nhóm trung tâm đơn thuần là $58,8 \%$. Tỉ lệ vét hạch nhóm trung tâm và hạch cổ một bên là $17,6 \%$ trong khi vét hạch nhóm trung tâm và hạch cổ hai bên là 23,5\%. Tỉ lê di căn hach chung là 41,7\%.

Các yếu tố liên quan đến tình trang di căn hạch: có mối liên quan giữa tỷ lệ di căn hạch với nam giới $(p=0,037)$.

\section{BÀN LUÂNN}

Trong nghiên cứu của chúng tôi, tuổi trung bình là 48,1 $\pm 11,2$, độ tuổi hay gặp nhất là $40-$ 65 chiếm $67,6 \%$ và tî̉ lệ nữ/ nam $=1 / 1,26$. Độ tuổi tương đồng với nghiên cứu của Roman với độ tuổi trung bình là 50,1, nhóm tuổi 40 - 65 chiếm tỉ lệ $47 \%{ }^{4}$ và cao hơn so với nghiên cứu của Raue, tuổi trung bình là $43,9 \pm 17$ trong đó nữ giới chiếm $58 \%^{6}$. Theo phân tích SEER trong 20 năm từ 1993 - 2013, ung thư tuyến giáp thể tủy ở nữ giới chiếm $58,1 \%$, nam giới chiếm $41,9 \%{ }^{7}$. Khám sức khỏe định kỳ tình cờ phát hiện khối u tuyến giáp là lý do vào viện chiếm tỉ lệ nhiều nhất với 55,9\% các trường hợp trong nghiên cứu của chúng tôi. Theo Lê Văn Quảng lý do khám thường gặp nhất là tự sờ thây khối u 
vùng cổ, chiếm $68,5 \%{ }^{8}$.

Trong nhóm bệnh nhân nghiên cứu, kích thước u trung bình là $19,1 \pm 11,4 \mathrm{~mm}$, u đơn độc chiếm $76,5 \%$. Kết quả của chúng tôi tương tự Lee $\mathrm{S}$. và cộng sự với kích thước u là $21 \pm 17 \mathrm{~mm}$, u 1 thùy chiếm $61,4 \%$. So với với ung thư giáp thể nhú, ung thư giáp thể tủy có kích thước lớn hơn có ý nghĩa thống kê, đường kính $2,3 \pm 1,5$ so với 1,1 $\pm 1,1 \mathrm{p}=0,001^{9}$. Trong nhóm ung thư tuyến giáp thể tủy di truyền tỉ lệ di căn hạch cổ trung tâm đơn thuần $45 \%$, di căn hạch cổ cùng bên $36 \%$, di căn hạch cổ đối bên 19\%. Trong nhóm ung thư tuyến giáp thể tủy lẻ tẻ tỉ lệ di căn hạch cổ trung tâm đơn thuần $50 \%$, di cằn hạch cổ cùng bên $57 \%$, di căn hạch cổ đối bên $28 \% 3$.

\section{KẾT LUÂ̂N}

Tuổi mắc bệnh trung bình là 48,1 $\pm 11,2$ tuổi, phần lớn trong nhóm 40-65 tuổi (chiếm 67,6\%). Tỉ lệ nữ/nam là $1 / 1,26$. Đa số bệnh nhân khám sức khỏe định kỳ phát hiện có u giáp chiếm tỉ lệ $55,9 \%$. Khối u chủ yếu ở 1 thùy $(85,3 \%)$, kích thước $\leq 2 \mathrm{~cm}(55,9 \%)$. Đánh giá trên siêu âm chủ yếu là TIRADS $4(76,5 \%)$. Tî lệ chọc hút tế bào kim nhỏ chẩn đoán ung thư tuyến giáp thể tủy hoặc nghi ngờ ung thư tuyến giáp thể tủy là $55,9 \%$.

Tỉ lệ di căn hạch chung là $47,1 \%$, tỉ lệ di căn hạch cổ nhóm 6 đơn thuần và kèm theo hạch cổ bển lần lượt là $31,2 \%$ và $62,5 \%$. Tỉ lệ di căn hạch tiềm ẩn là $21,1 \%$. Ung thư tuyến giáp thể tủy ở nam giới làm tăng tỉ lệ di căn hạch có ý nghĩa thống kê $(p<0,05)$.

TÀI LIẸU THAM KHẢO

1. Nguyễn Bá Đức. Dịch tễ học bệnh ung thư. Nhà xuất bản Y học; 2008.

2. Ricardo VL, Y.Osamura R. WHO classification of tumours of endocrine organs. IARC. 2017.

3. Scollo C, Baudin E, Travagli JP, et al. Rationale for central and bilateral lymph node dissection in sporadic and hereditary medullary thyroid cancer. J Clin Endocrinol Metab. 2003;88(5):2070-2075.

4. Roman S, Lin R, Sosa JA. Prognosis of medullary thyroid carcinoma: demographic, clinical, and pathologic predictors of survival in 1252 cases. Cancer. 2006;107(9):2134-2142.

5. Thyroid Cancer. NCCN guideline version 1. 2019.

6. Raue F. German medullary thyroid carcinoma/multiple endocrine neoplasia registry. German MTC/MEN Study Group. Medullary Thyroid Carcinoma/Multiple Endocrine Neoplasia Type 2. Langenbecks Arch Surg. 1998;383(5):334-336.

7. Milano AF. Thyroid Cancer: 20-Year Comparative Mortality and Survival Analysis of Six Thyroid Cancer Histologic Subtypes by Age, Sex, Race, Stage, Cohort Entry Time-Period and Disease Duration (SÉER*Stat 8.3.2) A Systematic Review of 145,457 Cases for Diagnosis Years 1993-2013. J Insur Med. 2018;47(3):143-158.

8. Lê Văn Quảng. Nhân xét đặc điểm lâm sàng và các phương pháp điều trị ung thư tuyến giáp tại Bênh viên $\mathrm{K}$ từ năm 1992-2000. Tạp Chí Y Học. 2002:323-326.

9. Lee S, Shin JH, Han BK, Ko EY. Medullary thyroid carcinoma: comparison with papillary thyroid carcinoma and application of current sonographic criteria. AJR Am J Roentgenol. 2010;194(4):1090-1094.

\section{NGHIÊN CỨU MộT Số ĐĂC ĐIỂM LÂM SÀNG VÀ ĐộT BIẾN GEN TRÊN BỆNH NHẦ PARKINSON KHỞI PHÁT SỚM}

\section{TÓM TẮT}

Đặt vấn đề: Trong những năm gần đây, bệnh Parkinson là đề tài mũi nhon đối với các bệnh thoái hoá thần kinh. Bệnh phổ biển thứ hai sau Alzeimer và chiếm $1,6 \%$ so với các bênh thân kinh. Trong bênh Parkinson, đột biến gen lặn tự phát có thể làm tẳng nguy cơ mắc Parkinson ớ người trẻ, ngay cả khi chi thừa hưởng môt bản sao của gen đột biến. Mục tiêu: Mô tả một sổ đặc điểm lâm sàng của bênh nhân Parkinson khởi phát sớm và mô tả một số đột biến gen trên bệnh nhân Parkinson khởi phát sớm. Đối

*Trường Đại học Y Hà Nội

Chịu trách nhiệm chính: Tô Thị Thu Hương

Email: dr.tohuong@gmail.com

Ngày nhận bài: 13.7.2021

Ngày phản biên khoa học: 8.9.2021

Ngày duyệt bài: 15.9.2021

\section{Tô Thị Thu Hương*, Nguyễn Văn Liệu*}

tượng và phương pháp nghiên cứu: nghiên cứu mố tả cắt ngang trên 30 bênh nhân có tuổi khởi phát nhỏ hơn 50 được chẩn đoán mắc bệnh Parkinson nguyên phát theo tiêu chuẩn của Ngân hàng Não thuộc Hội bệnh Parkinson Vương quốc Anh tại bệnh viện Lão Khoa trung ương, bệnh viện Bạch Mai. Trung tâm nghiên cứu Gen- Protein trường đại học $Y$ Hà Nội, nơi tiến hành các kỹ thuật di truyền phân tử. Kềt quả: tuổi khởi phát trung bình 41 với tỷ lệ nam: nữ là 1,9. Triệu chứng run hay gặp nhất với tỷ lệ 93,8\%. Và đột biến gen hay gặp là GBA phát trẻ

Tư khóa: Parkinson, đột biến gen, Parkinson khởi

\section{SUMMARY}

\section{THE STUDY SOME CLINICAL CHARACTERISTICS AND MUTATION IN EARLY-ONSET PARKINSON PATIENTS}

